Cipango Cahiers d'études japonaises

$17 \mid 2010$
La péninsule retrouvée

\title{
Reconstruire une identité nationale
}

Les études d'anthropologie physique dans le Japon postcolonial

(1945-2000)

Reconstructing a National Identity: Physical Anthropology in Post-Colonial

Japan (1945-2000)

\section{Arnaud Nanta}

\section{(2) OpenEdition}

Journals

Édition électronique

URL : https://journals.openedition.org/cipango/1126

DOI : $10.4000 /$ cipango. 1126

ISSN : 2260-7706

Éditeur

INALCO

Édition imprimée

Date de publication : 30 juin 2010

ISBN : 978-2-85831-195-8

ISSN : $1164-5857$

Référence électronique

Arnaud Nanta, « RECONStruire UNE IDENTITÉ NATIONALE », Cipango [En ligne], 17 | 2010, mis en ligne le 12 octobre 2012, consulté le 30 juin 2021. URL : http://journals.openedition.org/cipango/1126 ;

DOI : https://doi.org/10.4000/cipango.1126

Ce document a été généré automatiquement le 30 juin 2021.

\section{(c) (7) (8)}

Cipango est mis à disposition selon les termes de la Licence Creative Commons Attribution - Pas d'Utilisation Commerciale 4.0 International. 


\section{Reconstruire une identité nationale}

Les études d'anthropologie physique dans le Japon postcolonial

(1945-2000)

Reconstructing a National Identity: Physical Anthropology in Post-Colonial

Japan (1945-2000)

Arnaud Nanta

\section{NOTE DE L'AUTEUR}

Cet article est la version française remaniée de l'article : "Physical Anthropology and the Reconstruction of Japanese Identity in Postcolonial Japan", Social Science Japan Journal, Oxford, Oxford University, vol. 1-11, 2008, pp. 29-47, qui émane d'une conférence donnée en anglais le 11 novembre 2006 au colloque annuel de la German Association of Social Science Research on Japan (VSJF) à Hambourg. Je tiens à remercier Wolfram Manzenreiter, Iris Wieczorek, Laurent Nespoulous et Pierre F. Souyri pour leurs précieux conseils et relectures.

1 Cas unique dans l'histoire contemporaine, au Japon la Seconde Guerre mondiale s'est achevée en même temps qu'avait lieu la décolonisation, en 1945. Ce phénomène est à l'origine de nouveaux discours sur l'unicité et l'homogénéité ethnique du peuplement de l'archipel. Le travail d'Oguma Eiji ${ }^{1}$ a ainsi montré comment les représentations de l'identité nationale changèrent, dans les discours politiques et dans les sciences sociales, entre l'époque de l'empire colonial et la période postcoloniale. Du temps de l'empire colonial (1895-1945) en effet, l'anthropologie et l'archéologie avaient estimé que les Japonais étaient venus du continent asiatique. Elles avaient alors développé des modèles invasifs ou substitutifs et, dans ce cadre, les chercheurs de la Société d'anthropologie de Tōkyō (fondée en 1884) avaient conclu à une substitution du peuplement de l'archipel durant la Protohistoire. Après l'annexion de la Corée en 1910, les chercheurs des universités impériales de Tōkyō et de Kyōto considérèrent les Japonais comme un peuple métissé, composé à partir de plusieurs races issues de l'ensemble de l'Asie orientale. Au début du $\mathrm{xx}^{\mathrm{e}}$ siècle, Japonais et Coréens étaient donc 
considérés comme constituant "un seul et unique peuple» depuis les temps protohistoriques. Mais l'apogée et la chute de l'empire colonial virent un retournement total de ce paradigme des origines nationales : schématiquement, on peut considérer que les anthropologues commencèrent à souligner la spécificité raciale du "peuple japonais » vers 1940, pour ensuite soutenir, après 1945, l'idée de continuité raciale des Japonais sur l'archipel depuis la Préhistoire. Autrement dit, « de nombreuses années de recherche ont permis [à l'archéologie post-1945] de créer un récit objectif à même de remplir le vide laissé par le rejet du récit impérial qui présupposait d'accepter de façon absolue les anciennes chroniques». C'est ici qu'intervient l'idée de continuité biologique des Japonais, contre les mythes fondateurs de la dynastie impériale. Après la décolonisation « un mythe succédait à un autre $»^{2}$.

2 Le présent article a pour objectif de montrer comment apparurent des discours identitaires nouveaux dès le début de la période postcoloniale, comment des anthropologues majeurs tels Hasebe Kotondo ou Suzuki Hisashi soutinrent dès la seconde moitié des années quarante l'idée d'homogénéité raciale des Japonais, et, enfin, de quelle façon leur modèle en vint à constituer l'un des fondements du «mythe du peuple homogène » lorsqu'il fallut reconstruire l'identité japonaise après la perte de l'empire colonial. On tentera de compléter le travail d'oguma à partir de l'analyse de l'évolution de cette discipline qu'est l'anthropologie physique - sous-division de l'anatomie qui relève à la fois des sciences de l'homme et des sciences dures. Ceci nous amènera à analyser la question des "origines" des Japonais, à partir d'une interrogation sur la relation entre sciences dures et société. Les « sciences exactes » ne sont en effet pas moins vulnérables que les sciences humaines à l'idéologie d'une époque, et ce constat est d'autant plus juste pour l'anthropologie physique, qui traite d'enjeux nationaux tels les individus et les populations.

3 Il faut, pour bien comprendre les choses, se rappeler la distinction qui existe entre anthropologie culturelle (ou ethnologie) et anthropologie physique (ou anthropologie biologique). Leur objet ne se superpose pas exactement en effet, puisque la seconde étudie, outre l'altérité, également les populations du propre pays du chercheur. En outre, l'approche et les méthodes diffèrent. L'anthropologie culturelle tente de comprendre la structure et le fonctionnement des sociétés et, pour cette raison, est sensible aux modèles d'interprétation issus des sciences humaines (évolutionnisme, diffusionnisme, marxisme, structuralisme, etc.). L'anthropologie physique, de son côté, se rattache à la biologie qui l'influence directement, et classe la diversité du vivant en cherchant à en comprendre les processus de formation. Située au carrefour des sciences sociales et des sciences dures, l'anthropologie physique n'est pas exempte d'influences, celles-ci relevant en réalité davantage des préjugés diffus d'une époque que de grilles de lecture bien précises ${ }^{3}$. En réalité, le débat sur les «origines de Japonais ", comme naguère celui sur l'ethnogenèse des Français ou des Allemands, a été davantage déterminé par l'idée préconçue que se font les savants de leur communauté nationale que par leur activité scientifique ${ }^{4}$.

Le débat sur les origines des Japonais a de fait fasciné l'anthropologie physique japonaise depuis la fin du XIX ${ }^{e}$ siècle : celle-ci a été capable, en cent trente ans, de conclure une chose et son inverse selon le contexte politique, et même parfois les deux en même temps. La période d'après 1945 semble caractérisée par une anthropologie consensuelle, autour du paradigme hégémonique affirmant l'unité de "race» des Japonais. Or, si l'anthropologie universitaire de la capitale peut effectivement sembler 
avoir été unie, les années cinquante furent aussi le moment d'une recomposition des réseaux de chercheurs en différentes écoles. L'ancienne dichotomie entre le centre et la périphérie se renforça quand les universitaires partisans de l'idée de métissage en poste avant 1945 notamment dans les universités des colonies et nommés après la décolonisation dans des postes à la périphérie du Japon, se mirent à réactiver les discours d'avant 1945 dans un contexte de réethnicisation de l'identité japonaise. Dans les pages qui suivent, nous exposerons l'apparition du modèle de la microévolution, puis nous nous pencherons sur l'émergence de deux écoles d'anthropologie, l'une soutenant le métissage racial, et l'autre l'idée de pureté de la race. Ceci nous permettra de montrer comment le débat sur les "origines des Japonais» fit rage autour de nouvelles découvertes faites à Kyūshū par Kanaseki Takeo dans les années cinquante puis autour du Dual Structure Model. Cette analyse nous poussera à considérer les interactions entre discours scientifique, société et idéologie lorsqu'une société doit faire face à de grands changements.

\section{L'affirmation de la continuité de la race depuis la Préhistoire $^{5}$}

5 Dans les années trente, l'idée même d'un âge paléolithique (kyū sekki jidai 旧石器時代) sur l'archipel était récusée par les universitaires. Pour des chercheurs importants, tels que Kiyono Kenji 清野謙次 (1885-1955) ou Torii Ryūzō 鳥居龍藏 (1870-1953), le peuplement le plus ancien de l'archipel japonais remontait à quelques millénaires seulement. On admettait tout juste un peuplement autochtone indéterminé, voire, chez Torii, un "âge de pierre aïnou", sans précision de datation ${ }^{6}$. Selon les modèles dominants, les "Aïnous préhistoriques " auraient été repoussés par les «Japonais " vers l'actuelle île de Hokkaidō à partir de la période Yayoi. L'archipel aurait donc été le témoin d'une substitution du peuplement (Aïnous->Japonais). Surdéterminés par les paradigmes de leur époque, les savoirs scientifiques légitimaient la Weltanschaung de l'impérialisme continental (au sens de Hannah Arendt, c'est-à-dire un impérialisme annexionniste); ils historicisaient, comme l'avaient fait à leur manière les savants japonais depuis le XvIII ${ }^{\mathrm{e}}$ siècle (nous avons le même type de phénomène en Europe avec L'Iliade et L'Odyssée), le texte du Kojiki (712), qu'ils considéraient comme une métaphore de l'Histoire, et dont ils pensaient que les protagonistes étaient venus du continent.

Directeur de la section Anthropologie de l'université impériale de Tōkyō (fondée en 1938) ${ }^{7}$, et président, en 1951, de la Société japonaise d'anthropologie où il siégea dixsept ans, Hasebe Kotondo 長谷部言人 (1882-1969) peut être considéré comme le principal représentant de l'anthropologie physique japonaise d'après 1945 . Son travail s'inscrit dans le contexte de l'après-guerre et de l'après-décolonisation, période qui connut une explosion de l'intérêt du grand public pour l'anthropo-archéologie. En 1947, Hasebe redécouvre sur une étagère la réplique en plâtre d'un os de bassin retrouvé à Akashi. L'original, détruit lors des bombardements du printemps 1945, avait été exhumé en 1931 par Naora Nobuo 直良信夫 (1902-1985), qui avait alors été l'objet de violentes critiques pour avoir affirmé la nature paléolithique et japonaise de l'ossement. Son explication s'opposait en effet à l'idée d'un grand melting pot asiatique durant la Protohistoire qui s'imposait de plus en plus fortement avec la montée de l'empire colonial ${ }^{8}$. Naguère discret dans ces débats sur le peuplement préhistorique de l'archipel, Hasebe s'empare du bassin d'Akashi pour affirmer, devant la Société 
japonaise de géologie (Nihon chishitsu gakkai 日本地質学会), qu'il s'agissait assurément d'un os d'une femme du Pléistocène ${ }^{9}$. Il affirmait ainsi qu'il existait une continuité ethnique sur l'archipel depuis les premiers peuplements. Hasebe avait déjà proposé l'idée de la pureté ethnique des Japonais dans ses premiers papiers universitaires, en 1919 - soit au même moment que Gustav Kossinna (1858-1931) en Allemagne -, mais ne s'était plus exprimé ensuite sur ce sujet. Sa prise de position, deux ans après la fin de la guerre, constitue donc bien un brusque retournement au sein des débats. Elle est par ailleurs représentative de l'émergence sur le devant de la scène scientifique de ceux qui s'étaient opposés à l'assimilation durant l'empire colonial ${ }^{10}$. L'idée de la continuité raciale des Japonais n'est donc pas une nouveauté d'après 1945. Ce qui a changé alors, c'est qu'elle peut largement s'imposer. On peut penser que ce retournement est un effet direct de la décolonisation.

Hasebe affirma dès l'année suivante que le fameux bassin était d'une ancienneté comparable aux ossements de l'Homme de Java ou de l'Homme de Pékin - tous deux de classe Homo erectus $^{11}$. Il nomma son propriétaire Nipponanthropus akashiensis, c'est-à-dire l'Homme d'Akashi ${ }^{12}$. La référence à l'Homme de Pékin semble doublement importante : outre son ancienneté, l'Homme de Pékin avait en effet acquis un poids particulier, car il avait permis l'élaboration d'un modèle, celui du "Développement multirégional ", selon lequel les trois « races » (l'Européenne, l'Africaine et l'Asiatique) auraient évolué à partir de trois types différents d'Homo erectus, dont il était considéré comme le prototype asiatique. Autrement dit, sans être polygéniste, ce modèle affirmait la continuité des races humaines en remontant à différentes races d'Homo erectus. Hasebe avait rencontré à Tōkyō en 1937 son inventeur, Franz Weidenreich (1873-1948), celui-là même qui avait supervisé les fouilles à Zhoukoudian 周口店 (Beijing) dans les années trente ${ }^{13}$. Trouver opportunément un Homme d'Akashi aussi ancien que l'Homme de Pékin ne lui permettait-il pas d'avancer l'ancienneté et la continuité de la race japonaise sur l'archipel même, en dehors de toute influence continentale ? De nouvelles découvertes allaient pouvoir le conforter. Les archéologues mirent à jour en 1949, à Iwajuku, une présence humaine sur le sol japonais remontant au Paléolithique ${ }^{14}$. Celleci balaya complètement le paradigme archéologique de l'époque coloniale selon lequel la Préhistoire japonaise n'aurait duré que quelques milliers d'années.

Découvrir à l'archipel une longue préhistoire, c'était permettre d'en penser la population indépendamment des influences extérieures, en mettant en avant la continuité du peuplement sur le sol japonais. C'est ainsi que l'on vit se développer dans les années 1947-1949 une pensée que l'on pourrait qualifier d'autochotonisme ${ }^{15}$. Son apparition correspond à l'émergence de nouveaux chercheurs au sein des institutions. Le «pur débat d'idées » correspond en effet à un retournement complet du rapport de forces antérieur : en 1945-1950, tous les anciens soutiens du paradigme des origines continentales sont soit décédés (beaucoup sont morts entre 1937 et 1944), soit nommés dans des régions périphériques de l'archipel, à Kyūshū ou à Hokkaidō notamment. Les universitaires que l'historien Oguma fait relever de « la pensée insulariste » (shimaguni shisō 島国思想 ${ }^{16}$ avaient en effet pris le contrôle des institutions-clefs de la capitale tandis qu'ils étaient occupés par la guerre ou par leur travail dans les colonies.

9 En fait, le discours "autochtoniste », constituante centrale du "mythe du peuple homogène ", fut formulé autour de 1950 dans l'ensemble des champs des sciences sociales par des archéologues et des anthropologues, mais aussi des historiens et des linguistes, qui critiquaient ce qu'ils appelaient l'«idéologie d'avant-guerre». Ils 
reprochaient à celle-ci d'associer mythe et Histoire et d'avoir légitimé l'impérialisme annexionniste en portant le discours des "origines communes" entre Japonais et populations colonisées. En opposition à l'historiographie centrée sur l'empereur qui émanait de la droite, ces chercheurs "progressistes " contribuèrent à forger une nouvelle « histoire nationale » après la perte de l'empire colonial. Celle-ci s'est appuyée notamment sur la conviction que les Japonais possédaient une unité territoriale et raciale, strictement comprise dans les frontières politiques du Japon métropolitain, et remontant jusqu'à la Préhistoire ${ }^{17}$. Ainsi, se produisit après 1945 une " réethnicisation " des discours sur le peuple japonais - pensé dorénavant comme une entité de race attachée au territoire de l'archipel. Logiquement, on constata une «japonisation du Jōmon $»^{18}$ : celui-ci faisait dorénavant partie de l'histoire du peuple japonais. Cette japonisation émanait des ethnicistes qui n'avaient pu prendre la parole du temps des colonies, mais aussi des anticolonialistes des années cinquante. Le Japon présente ainsi un cas intéressant où une " histoire nationale ", habituellement produite dans la phase de fondation de l'État-nation, fit suite à une historiographie impérialiste, dans l'ordre inverse de ce que l'on peut attendre. De ce fait, il est malaisé de distinguer, dans les décennies cinquante et soixante, entre les discours des historiens marxistes, des libéraux et des nationalistes de gauche, voire des anticolonialistes, car tous, malgré leur diversité, accordent une place centrale dans leurs discours à un même concept, celui de "peuple» japonais, en opposition aux discours monarchistes des conservateurs ${ }^{19}$. L'idée de peuple devenait un vecteur commun dans un contexte plus général de critique du système impérial.

Hasebe participe de ce mouvement, comme en témoignent deux ouvrages successifs : La formation du peuple japonais, en $1949^{20}$, puis Les ancêtres des Japonais, en $1951^{21}$. Est ici traduit par «peuple» le mot japonais minzoku 民族, qui se rapproche plutôt de l'idée allemande de Volk en ce qu'il implique une unité ethnique et culturelle là où le terme français oscille entre unité ethnique et unité politique ${ }^{22}$. Dans ces deux ouvrages, Hasebe concluait que l'homogénéité ethnique des Japonais les distinguait des nations continentales ainsi que de la minorité aïnoue du nord, position totalement intenable à peine dix ans plus tôt $t^{23}$. Il critiquait également la conception fixiste des races qui prévalait dans la première moitié $\mathrm{du} \mathrm{xx}^{\mathrm{e}}$ siècle et même avant, pour reprendre à la place une conception néolamarckienne ${ }^{24}$ de l'histoire de la population japonaise, saisie dans un processus d'évolution constant du passé jusqu'au présent. Pour Hasebe, les hommes de l'âge de la pierre, loin d'être les «barbares aïnous» décriés naguère, étaient sans doute les ancêtres des Japonais.

La raison pour laquelle la culture des céramiques à décors cordés [jōmon 繩文] parâit différente de la culture japonaise vient d'un écart important dans le degré de développement technologique ainsi que de l'absence d'outils métalliques dans la première. Il est cependant évident que ces deux cultures relèvent essentiellement d'une lignée unique [dōitsu keitō 同] 一系統 $]^{25}$.

11 Ainsi, les hommes de la période préhistorique Jōmon furent reconsidérés comme les ancêtres en filiation directe des Japonais actuels, sans aucun métissage ethnique durant la période protohistorique Yayoi ${ }^{26}$. On comprend alors que ce soit après 1945 que se mit en place au Japon une "archéologie nationale", c'est-à-dire une archéologie qui recherche les ancêtres du "peuple » sur le « sol national », comme on avait pu le faire autour du mythe gaulois en France lors des grandes fouilles à Alésia sous le Second Empire (1852-1870), puis avec l'« Histoire nationale» durant la III République ${ }^{27}$. Le modèle évolutionniste de l'école de Hasebe considérait que les caractères 
morphologiques, c'est-à-dire la forme des ossements, n'étaient pas des données fixes, mais évoluaient avec les siècles. Les différences constatées dans le morphotype et dans la culture matérielle ne devaient donc plus s'expliquer comme les produits d'une différence "raciale ", ainsi que l'avait prétendu l'anthropologie préhistorique d'avant 1945, mais comme le résultat d'une phase de l'évolution historique. Le concept de « microévolution » dû à Weidenreich était mobilisé afin d'expliquer la «formation des Japonais ». Au-delà de ces variations historicisées dans les caractéristiques du squelette, «l'essence du peuple» (minzoku no honshitsu 民族の本質) restait « égale à elle-même, comme par le passé ", concluait Hasebe ${ }^{28}$.

Ce discours, dont on retrouve les circonvolutions dans tous les États-nations, évoque les modèles gallo-celtiques d'ethnogenèse des Français ou le travail de Paul Broca (1824-1880) quand ce dernier affirmait l'évolution progressive de la forme du crâne des Parisiens depuis le Moyen-Âge en suivant un lamarckisme peu clair (Broca était antidarwinien et fut, en réalité, acquis tardivement au transformisme). Ou le travail de Kossinna qui considérait dans ses travaux publiés autour de la Grande Guerre que la « race allemande» avait évolué sans métissage depuis la Préhistoire ${ }^{29}$. Chez Hasebe, comme chez ces grands noms de l'anthropologie occidentale, la recherche travaillait à partir de l'idée préconçue que les savants se faisaient de leur propre pays.

\section{Suzuki Hisashi, l'école de Tōkyō et le modèle de la microévolution}

La reconstruction du Japon après 1945, notamment celle des grandes villes sinistrées durant la guerre (Tōkyō, Nagoya ou encore Ōsaka), permit de mettre à jour des cimetières de milliers de squelettes issus de toutes les périodes historiques. La conservation de ceux-ci fut centralisée à l'Université de Tōkyō et ils servirent de matériaux de recherche à Suzuki Hisashi 鈴木尚 (1912-2004), un ancien élève de Koganei Yoshikiyo 小金井良精 (1858-1944) et de Hasebe à l'université impériale de Tōkyō, nommé comme anthropologue dans cette même université à la fin des années quarante. Travaillant sur l'ensemble de ce corpus, Suzuki s'efforça dans les décennies cinquante et soixante de démontrer la continuité génétique des habitants de l'archipel depuis les temps préhistoriques. Il fut donc un des protagonistes scientifiques principaux du processus d'énonciation du mythe du peuple homogène et contribua de manière décisive à l'affirmation de la spécificité japonaise en tant que "race » lorsqu'il fallut repenser l'identité japonaise sans l'empire colonial.

Le travail de Suzuki après-guerre débuta en mars 1950 par une enquête dans l'enceinte du prestigieux complexe religieux du Chūsonji 中尊寺 à Hiraizumi 平泉, dans le Nordest du Japon ${ }^{30}$. Il s'agissait, par une étude anthropométrique, de déterminer la nature « raciale » de deux seigneurs de la famille Fujiwara du nord enterrés dans ce temple, Hidehira 藤原秀衡 et Yasuhira 藤原泰衡 : étaient-ils des descendants d'« Aïnous » ralliés à la cour ou bien des "Japonais " ${ }^{31}$ ? Les résultats de l'analyse, dont l'intérêt paraissait assez grand pour que le journal Asahi la finance et publie le rapport d'enquête (1950), montrèrent qu'ils étaient bien racialement "japonais ", contrairement à ce qu'avaient conclu les chercheurs avant 1945. Suzuki expliqua par exemple: "nous fûmes étonnés de ne trouver absolument aucun trait aïnou sur le visage de Hidehira $»^{32}$. Ainsi, le Nord du Japon (ou plutôt de Honshū, au Sud de l'actuelle Hokkaidō) aurait de tout temps été peuplé par des « Japonais ». 
15 En parallèle de la controverse permanente sur les «origines » du peuplement, l'idée «autochtoniste» put s'exprimer aussi dans la réécriture de l'histoire japonaise, marquée par une ethnicisation de ses protagonistes : le peuplement de l'archipel avait donc de tout temps été « racialement japonais ». Suzuki étudia également les caractères morphologiques des shōgun Tokugawa enterrés au Zōjōji 増上寺, à Tōkyō (programme de recherche de 1958-1960) ${ }^{33}$. Ce travail visait à critiquer les théories des deux races antagonistes en vogue en Europe occidentale depuis le XVIII ${ }^{\mathrm{e}}$ siècle et qui avaient eu une certaine influence au Japon à la fin du $\mathrm{XIX}^{\mathrm{e}}$ siècle ${ }^{34}$. Selon elles le morphotype aristocratique des nobles d'Ancien Régime s'expliquait par l'existence d'une race conquérante supposée différente de la race autochtone ${ }^{35}$. La thèse avait finalement été très critiquée en Europe au $\mathrm{XIX}^{\mathrm{e}}$ siècle alors qu'émergeaient les États-nations "homogènes ». Suzuki s'apprêtait à mener à son tour la critique de cette ancienne théorie. Selon lui, les différences morphologiques constatées entre les aristocrates et les roturiers de la période d'Edo (1603-1867) ne pouvaient s'expliquer par une différence de "race ", comme dans le cadre des modèles invasifs, mais plutôt par les effets d'un meilleur environnement de vie, les modifications individuelles se transmettant ensuite génétiquement. En cela il suivait la logique néolamarckienne de Hasebe afin de démontrer l'unicité raciale des Japonais.

16 Suzuki réalisa également des fouilles archéologiques en Israël en $1961^{36}$ et fut lié aux découvertes $\mathrm{d}^{\prime}$ " hommes paléolithiques" à Mikkabi ${ }^{37}$, à Ushikawa 牛川人 et à Minatogawa $^{38}$, ainsi qu'en d'autres lieux d'okinawa. C'est lui qui rédigea les rapports ostéométriques pour toutes ces découvertes.

17 Son modèle de la microévolution (jp. : shō shinka 小進化) ${ }^{39}$ fut d'abord présenté aux États-Unis en 1956, lors du Fifth International Congress of Anthropological and Ethnological Sciences à Philadelphie ${ }^{40}$. Il fut exposé pour la première fois en japonais en 1960, dans un collectif commémorant le centenaire de L'Origine des Espèces (1859) de Charles Darwin (1809-1882) ${ }^{41}$, puis en 1964 dans la collection Histoire du Japon de l'éditeur Iwanami, dirigée par l'historien Ienaga Saburō 家永三郎 (1913-2002) ${ }^{42}$. Une synthèse de ce modèle fut encore publiée en anglais en 1969 dans le Journal of the Faculty of Science de l'Université de Tōkyō ${ }^{43}$, sous le titre "Microevolutional Changes in the Japanese Population from the Prehistoric Age to Present-Day ». Le modèle de Suzuki fut hégémonique après la décolonisation et durant toute la période de la guerre froide : l'idée d'une "continuité génétique totale sur l'archipel depuis la période Jōmon » ${ }^{44}$ constituait toujours la position officielle de la Société japonaise d'anthropologie en $1984^{45}$

18 Suzuki reprenait en fait le schéma général posé par Hasebe, auquel il apportait des arguments anthropométriques - grâce aux nombreux matériaux ostéologiques découverts dans les années cinquante - ainsi que l'idée d'une «brachycéphalisation » (arrondissement de la forme du crâne vu de dessus) progressive au cours de l'histoire ${ }^{46}$. Les présupposés de ce modèle furent en réalité d'abord mobilisés lors du programme d'étude portant sur les jumeaux au Japon intitulé « Sōseiji kenkyū han » 双生児研究班 (1949-1960), et réalisé sur commande de la Japan Society for the Promotion of Science et $d u$ ministère de l'Éducation ${ }^{47}$. On peut y saisir les prolégomènes du modèle de la microévolution de Suzuki, notamment ses présupposés fondamentaux et son mode de démonstration, dans la formulation de sa pensée.

Dans son rapport sur " L'anthropométrie des jumeaux ${ }^{48}$, Suzuki rappelait tout d'abord que la particularité essentielle des vrais jumeaux était de posséder en commun un 
génotype identique ${ }^{49}$. Les différences constatées et mesurées sur le phénotype, c'est-àdire sur le corps, et plus particulièrement sur les crânes pour Suzuki, ne pouvaient donc être expliquées que comme le résultat d'une l'action de l'environnement, comme dans la théorie lamarckienne. Et c'est le même genre de raisons qui expliquaient les différences constatées entre les crânes du Jōmon récent et du Yayoi ancien. En réduisant ainsi à du superficiel, au sens littéral, les différences constatées sur le morphotype et notamment sur les crânes, Suzuki mit en avant l'idée de continuité d'une essence japonaise, par ailleurs jamais précisée ni bien cernée ${ }^{50}$. Analysant l'évolution de vingt mesures effectuées sur le crâne, depuis la période Jōmon jusqu'à la période contemporaine, Suzuki proposait d'y voir une variation explicable par des effets de l'environnement et concluait que l'idée de continuité du sang jusqu'à nos jours était tout à fait pertinente ${ }^{51}$.

Après un examen des squelettes de toutes les périodes [préhistorique et historiques] depuis le Jōmon jusqu'à nos jours, nous pensons que les transformations observées sur les crânes sont continues [renzoku shita mono 連続したもの]; elles ne montrent aucune rupture. Sur le plan de l'origine des Japonais, cela signifie que les Japonais contemporains proviennent directement des hommes de la période [préhistorique] Jōmon.

Cette position, affirmant l'homogénéité et la continuité biologiques des Japonais (c'està-dire affirmant les Japonais comme « race »), devint la doxa académique dans toutes les grandes publications des décennies 1950-1970, quel que soit leur positionnement. L'idée était d'ailleurs soutenue par Hasebe, qui présidait alors les principales institutions de la discipline et qui allait en permanence dans le sens du propos de Suzuki. Ceci montre le poids des réseaux et des enjeux de pouvoir dans le monde universitaire : les revues spécialisées publiaient des articles abondant dans le sens du modèle de la microévolution. Celui-ci était cependant critiqué par d'anciens anthropologues coloniaux tels que Ueda Tsunekichi 上田常吉 (1887-1966), Imamura Yutaka 今村豊 (1896-1971) ou Kohama Mototsugu 小濱基次 (1904-1970) qui avaient travaillé à l'université impériale de Keijō (Séoul) avant $1945^{52}$. La nouvelle génération d'archéologues de l'école de Kyōto, tel Kobayashi Yukio 小林行雄 (1911-1989), bien qu'adoptant une posture critique, déserta par contre le débat sur la race, s'éloignant ainsi de ses prédécesseurs de l'époque coloniale. Cela peut surprendre quand on se rappelle que l'école d'archéologie de Kyōto avait tenté vers 1917-1920 d'affirmer, en collaboration justement avec Hasebe, la continuité biologique des Japonais depuis la Préhistoire $^{53}$. La nouveauté provint de l'entrée dans le débat d'un autre anthropologue, lui aussi de retour des colonies, Kanaseki Takeo, qui non sans paradoxe historique élabora un modèle alternatif à celui de Suzuki.

\section{Kanaseki Takeo, les réseaux coloniaux et la thèse du métissage}

Kanaseki Takeo 金関丈夫 (1897-1983), un ancien collègue de Kiyono à Kyōto au début des années trente, avait été anatomiste à l'université impériale de Taihoku (Taipei), dans la Taïwan coloniale. De retour au Japon en 1949, il fut nommé professeur en anatomie à l'Université de Kyūshū. Cette localisation géographique excentrée dans le Sud-Ouest du Japon permit à Kanaseki et à ses collègues, tels Naitō Yoshiatsu 内藤芳篤 (né en 1925) des universités de Nagasaki et Nagai Masafumi 永井昌文 (né en 1924), de découvrir en 1953-1957 des sites Yayoi renfermant des champs d'urnes funéraires à la pointe ouest de Honshū (Doigahama 土井ヶ浜) et au nord de Kyūshū (Mitsunagata 三津 
永田). Ces sites furent immédiatement comparés à ceux de Corée, qui étaient bien connus de ces chercheurs ${ }^{54}$. Leurs rapports de fouilles pour les sites de Doigahama et Mitsunagata ne furent pas publiés dans la Revue d'anthropologie (c'est-à-dire à Tōkyō), mais dans le bulletin Études anthropologiques (Jinruigaku kenkyū 人類学研究) de l'Université du Kyūshū, spécialement créé pour l'occasion, ce qui montre combien il était difficile de publier contre Suzuki dans les principales revues ${ }^{55}$. Kanaseki et Naitō étaient convaincus que les porteurs de la culture Yayoi n'étaient pas de la race autochtone décrite par Suzuki mais étaient venus du continent, et avaient bouleversé la société de l'archipel. En un mot, ils étaient opposés à l'idée de peuplement japonais homogène.

La controverse avec les « Tokyoïtes » apparut notamment autour de trois publications : l'ouvrage collectif d'anthropologie physique intitulé Le peuple japonais (Nihon minzoku 日 本民族) publié par la Société japonaise d'anthropologie en 1952 ; les Cours d'archéologie du Japon de 1955-56, dirigés notamment par l'ancien numéro un de l'archéologie en Corée, Fujita Ryōsaku 藤田亮策 $(1892-1960)^{56}$; et enfin la série Histoire du Japon (Nihon rekishi) chez Iwanami (1962-1964). Cette dernière, déjà citée, développait une conception continuiste du peuplement japonais. Il ne pouvait d'ailleurs en être autrement, tant la prégnance de l'idée de continuité du peuplement était forte chez les historiens marxistes et libéraux de l'époque ${ }^{57}$. La collection d'archéologie comportait elle une section portant sur les squelettes du Jōmon rédigée par Suzuki, dont on sait la position sur cette question de la continuitée ${ }^{58}$. Toutefois, du fait des importantes découvertes faites dans l'ouest du Japon, la partie sur les squelettes Yayoi était présentée par Kanaseki, au sein d'un volume spécifique portant sur les «questions en débat». Le texte de Kanaseki, "La question de la race $»^{59}$, contredisait Suzuki. Il constituera plus tard la pierre angulaire de la critique du modèle "autochtoniste ". Cependant, à la fin des années cinquante, il fut vivement critiqué dans les réunions scientifiques tels les symposiums des anthropologues. Il en est ainsi par exemple du $13^{\mathrm{e}}$ Congrès commun de la Société japonaise d'anthropologie et de l'Association japonaise d'ethnologie, tenu en 1958 à Niigata, et dont le thème était «Les Origines des Japonais $»^{60}$. Le modèle «autochtoniste» de Suzuki satisfaisait la majorité des universitaires : «l'ambiance était telle que ceux qui pensaient que "les Japonais avaient reçu quelque influence d'arrivants venus de l'extérieur" étaient considérés comme des hérétiques " put-on rapporter ${ }^{61}$. Il serait pourtant délicat de conclure à la grande influence sociale des anthropologues : l'idée de microévolution était plutôt le reflet des attentes sociales du Japon postcolonial, ce qui explique sa position hégémonique au sein des discours scientifiques.

Le "modèle du métissage", développé par Kanaseki et ses collègues, insistait principalement sur trois points :

1. Le peuple japonais se serait formé par métissage de deux races, au moins pour la région historique de Kyōto (Kanaseki ne se prononçait pas pour le Kantō et le Nord-est, régions considérées de moindre importance par les chercheurs du Japon occidental);

2. Les migrants allogènes auraient des traits morphologiques proches de ceux des Coréens du Sud: grande stature et dolichocéphalie (crâne de forme allongée), par ailleurs caractères morphologiques souvent reconnus aux « races conquérantes »;

3. Le métissage se serait étendu sur plusieurs siècles et les caractères allogènes perdureraient, en particulier dans le Centre et l'Ouest de l'archipel. 
Pour Kanaseki, comme pour Suzuki finalement, race et culture se superposaient: la dénomination «hommes du Yayoi » (ou «hommes du Jōmon») ne signifiait pas «les populations ayant habité sur l'archipel durant la période Yayoi », mais désignait plutôt une entité biologique c'est-à-dire une « race Yayoi ». En cela, les théories d'ethnogenèse composées après-guerre étaient toutes racialistes: elles saisissaient les groupes humains comme autant d'entités biologiques - quelle que soit leur définition concrète et analysaient l'histoire comme une série de chocs entre ces " races", ou comme processus de la formation de celles-ci.

5 Dans «La question de la race », Kanaseki tentait une comparaison entre les squelettes «Yayoi » de Mitsunagata et Doigahama et des squelettes coréens, en s'appuyant sur des rapports de 1935 d'Ueda Tsunekichi (à Séoul) qui signalaient une " race plus grande » aux extrémités nord et sud de la péninsule coréenne. L'idée de métissage défendue du temps des colonies par Kiyono connut ainsi une pérennité au sein des débats d'ethnogenèse qui suivirent la décolonisation. Les discours et matériaux des savoirs coloniaux se virent dans le même temps remobilisés par les soutiens de l'idée de métissage. Il s'agit là d'un paradoxe historique remarquable, qui ne peut s'expliquer que par le repli identitaire et nationaliste du Japon d'après 1945.

Parallèlement à ce travail mené au Sud, à l'Université de Kyūshū, par Kanaseki, une nouvelle école anthropologique, défendant elle aussi l'idée de métissage, était en train de se constituer au nord du Japon, dans les universités de Sapporo et de Hokkaidō, autour de Yamaguchi Bin 山口敏 (né en 1931) et surtout de Hanihara Kazurō 埴原和郎 (1927-2004). Mais à la différence de Kanaseki et de ses collaborateurs, ces derniers allaient reprendre à zéro la réflexion sur le processus de l'évolution lui-même (comme le fit, très différemment, Suzuki) en étudiant les métis nippo-américains nés durant l'occupation. Ceux-ci, expliqua-t-on, avaient un morphotype intermédiaire de celui des deux parents (Noir et Asiatique, pour les cas étudiés par Hanihara et Suda Akiyoshi 須 田昭義 (1900-?) dans les années soixante). Ne pouvait-on pas penser que le morphotype médian constaté au milieu du Japon durant le Yayoi révélait qu'il y avait eu métissage au début du Yayoi ? La thèse permettait par ailleurs de repenser les « relations raciales » entre les populations aïnoues, celles d'Okinawa et « les Japonais » (cf. infra). Elle joua plus tard, dans les décennies 1970-1980, un rôle essentiel dans la critique formulée à l'encontre du modèle de la microévolution.

Kanaseki considérait son modèle comme une critique de «l'idéologie d'avant-guerre de la pureté raciale » et utilisait cet argument contre Suzuki et Hasebe. En face, comme on l'a noté, Hasebe estimait que son travail permettait une critique des discours colonialistes et dogmatiques d'avant-guerre qui tenaient pour sacrée l'étude philologique des mythes impériaux ${ }^{62}$. Des arguments semblables étaient ainsi utilisés par chaque camp afin d'invalider le discours de l'autre. Kanaseki jugeait notamment que le propos de Hasebe et Suzuki constituait une résurgence du « discours d'avant 1945 du bansei ikkei» (万世一系 « dix mille générations ininterrompues ») du peuple Yamato ${ }^{63}$. Mais, en réalité, ce discours d'avant 1945 portait sur l'empereur et non sur le peuple, considéré à l'époque comme métissé, comme on l'a noté. De plus, si les discours de Hasebe et de Suzuki doivent être replacés dans le contexte social et politique de renfermement identitaire de l'archipel sur lui-même après 1945, le discours de Kanaseki avait lui aussi une dimension idéologique. Si Suzuki affirmait l'homogénéité ethnique des Japonais, Kanaseki rapprochait Corée et Japon en s'appuyant sur des données produites par les savoirs coloniaux dans le contexte de l'impérialisme 
continental d'avant 1945. Entre Kanaseki et Suzuki, c'étaient donc deux conceptions différentes de la japonité qui s'affrontaient. Kanaseki soulignait également la proximité entre les squelettes Yayoi de Mitsunagata ou de Doigahama, d'une part, et d'autre part, ceux de sites de la moitié Ouest du Japon comme Tsukumo 津雲 ou Kō 国府 ${ }^{64}$, sites justement fouillés par ses anciens professeurs de l'université impériale de Kyōto, Hamada Kōsaku 濱田耕作 (1881-1938) et Kiyono en 1917-192065. Chacun s'appuyait ainsi en priorité sur les matériaux de son propre courant de recherche.

La nouvelle édition (1966) des Cours d'archéologie du Japon ${ }^{66}$ laissa une plus grande place aux détracteurs de Suzuki. Les anthropologues Shima Gorō 島五郎 (1906-1983), formé à l'université impériale de Keijōo (Séoul) dans la Corée coloniale, et Terakado Yukitaka 寺 門之隆 (1924- ?) y réfutaient clairement son modèle. Kanaseki y écrivit également, en réaffirmant la proximité raciale entre les populations protohistoriques de l'archipel et les Coréens du Sud. Il s'appuyait pour cela à nouveau sur les résultats de l'anthropologie de « l'école de Keijō » d'avant 1945, à laquelle avait participé Shima, et notamment sur un texte de 1932 d'Imamura Yutaka ainsi que sur un rapport de Suzuki Makoto 鈴木誠, autre spécialiste des crânes de Coréens à cette époque ${ }^{67}$.

De façon remarquable, le débat sur les « origines » s'est systématiquement focalisé sur la question de la « race ». La thématique de l'apparition de la riziculture inondée aurait permis aux chercheurs d'étudier la structure des sociétés du passé. Mais elle ne les intéressait que pour déterminer si ces transformations qu'avait connues l'archipel avaient été imposées par une "race" étrangère ou avaient été menées par «les Japonais » eux-mêmes. Inversement, la controverse sur l'ethnogenèse des Japonais mettait à jour une ironie de l'histoire: d'un côté les tenants du modèle fermé du peuplement insistaient sur l'idée de continuité raciale au nom d'une critique des discours de l'impérialisme annexionniste d'avant 1945; de l'autre, les tenants d'un modèle ouvert (le groupe de Kanaseki) s'appuyaient explicitement sur les travaux et discours colonialistes des années trente pour défendre l'idée d'un peuplement japonais aux origines métissées. Bien que les positions défendues par les deux camps puissent paraître paradoxales, cette situation pose en réalité le problème du rapport entre oppression et assimilation au temps des empires coloniaux, ainsi que celui du rapport entre État-nation et identité fermée dans le monde d'après les décolonisations. Car l'État-nation qui a été reconstruit en rupture avec le temps colonial s'est avéré au final producteur d'une identité plus fermée que celle développée du temps de la colonisation. Ce sont là des points qui mériteraient sans doute davantage d'attention au sein du courant dit des postcolonial studies, pour comprendre les renouveaux identitaires actuels.

Comme leurs travaux s'appuyaient sur des rapports de l'époque coloniale rédigés dans un contexte politique affirmant la proximité raciale nippo-coréenne, il n'est pas étonnant que Kanaseki et son collègue Nagai ${ }^{68}$ soient arrivés à la même conclusion que celle soutenue du temps de la colonisation, c'est-à-dire à l'idée d'une grande similitude ou proximité ethnique entre Japonais et Coréens. Mais était-ce là pour autant une « résurgence de l'impérialisme "? Si les interrogations ainsi que les réponses apportées sont toujours déterminées par l'époque et le contexte, il faut par contre bien distinguer, ici pour l'avant et l'après 1945, entre l'analyse (le constat, fait par ces chercheurs, d'une proximité morphologique) et l'interprétation. Après la décolonisation, il ne s'agissait plus de justifier une quelconque annexion de la Corée 
«au nom de la race», mais plutôt d'inviter à ouvrir l'archéologie japonaise vers la Corée et le continent au lieu de la refermer sur l'archipel.

\section{Consécration de l'autochtonisme et émergence du Dual Structure Model}

Dans les décennies 1950-1970, le modèle du métissage protohistorique ne parvint pas à s'imposer face à l'idée hégémonique d'une lignée japonaise ininterrompue défendue par les universitaires de la capitale. Kanaseki fut critiqué non seulement par la Société japonaise d'anthropologie, mais aussi par certains de ses nouveaux collaborateurs. C'est le cas de Naitō Yoshiatsu, qui publia, en 1971, une critique du modèle du métissage ralliant finalement le modèle de la microévolution ${ }^{69}$. Il y expliquait que les squelettes «de la période Yayoi » de l'ouest et du sud de Kyūshū étaient peu différents de ceux "des hommes préhistoriques Jōmon », et que, par conséquent, ceux de Mitsunagata et de Doigahama ne constituaient rien d'autre qu'une exception locale portant sur un nombre très restreint d'individus. L'argument allait être ensuite repris par Suzuki.

Les décennies 1960-1970 marquèrent donc la consécration de Suzuki : président de la Société japonaise d'anthropologie (1970-1976) ${ }^{70}$, bénéficiant du soutien de généticiens renommés ${ }^{71}$, membre en 1969 du Scientific Council of Japan (Nihon gakujutsu kaigi 日 本学術会議), directeur de la section anthropologie au Muséum national des Sciences (Kokuritsu kagaku hakubutsukan 国立科学博物館) en $1972^{72}$. Le modèle de la microévolution des Japonais, élaboré par Hasebe dès la chute de l'empire colonial puis démontré scientifiquement par Suzuki dans les années cinquante, domina non seulement l'anthropologie physique, mais aussi le regard de l'ensemble des sciences humaines et sociales dans les décennies 1960-1970. Le paradigme du melting pot des peuples autour de l'empereur, hégémonique du temps des colonies, avait disparu en même temps que l'empire colonial pour un autre paradigme, celui d'un " peuplem ent homogène » ayant de tout temps habité l'archipel japonais. Cependant, chez les deux camps en présence, filiation continue ou métissage, le modèle purement invasif (c'està-dire le modèle de la substitution intégrale du peuplement durant la Protohistoire) était rejeté, le débat sur les origines des Japonais passant après la colonisation d'une discussion sur le lieu géographique d'«origine " de la race à une réflexion sur le processus d'« ethnogenèse » des Japonais.

Le modèle de la microévolution bénéficia d'une meilleure réception au sein des autres disciplines des sciences sociales du fait de cette reconstruction de l'identité japonaise comme identité fermée sur elle-même après la perte de l'empire colonial. On retrouve ce discours "insulariste " chez des historiens et intellectuels majeurs de toutes tendances politiques tels Inoue Kiyoshi 井上清 (1913-2001), Ienaga Saburō ${ }^{73}$, Maruyama Masao 丸山眞男 (1914-1996) ${ }^{74}$ ou Ōno Susumu 大野晋 (né en 1919) ${ }^{75}$. Il serait osé d'en conclure que l'anthropologie a influencé les autres sciences humaines et sociales. Bien plus tôt, toutes les sciences de l'homme et de la société (y compris l'anthropologie) s'inséraient dans cette idée paradigmatique d'après 1945 d'une "race japonaise non métissée ", ainsi que le travail d'Oguma l'a montré ${ }^{76}$. L'histoire du Japon du célèbre historien marxiste Inoue Kiyoshi illustre bien le poids de ces grilles de lecture racialistes dans les sciences humaines. Dans ce livre de 1963, Inoue expliquait ${ }^{77}$ :

Nous, les Japonais, formons une même race et habitons sur le même sol, l'actuelle terre de

l'archipel du Japon, depuis les temps les plus anciens jusqu'où l'on peut remonter dans notre 
Histoire. Il y eut bien parfois quelque métissage avec d'autres races durant cet intervalle de temps. Mais jamais il ne se produisit de substitution de la race par fait de conquête, ni de métissage sur une grande échelle. Les Japonais ont développé leur société et leur civilisation sans aucune rupture, depuis les temps de la barbarie primitive jusqu'au niveau de premier ordre de la civilisation actuelle. Ceci constitue un trait caractéristique de l'Histoire japonaise. universitaires progressistes. Or la question des «origines » est une obsession liée à la modernité nationale et à l'État-nation plutôt qu'à un cadre théorique. Le discours ethniciste des historiens progressistes japonais relève d'un nationalisme de gauche dont on peut penser qu'il a été bien plus influencé par le contexte postcolonial que par le marxisme. Le marxisme a certes eu une portée essentielle sur les sciences humaines et sociales dans le monde entier depuis le début du $\mathrm{xx}^{\mathrm{e}}$ siècle. Au Japon, il a fonctionné comme un cadre de pensée moderne à l'influence très générale, qui a marqué tant la gauche que la droite ${ }^{78}$. Que l'archéologie antique et protohistorique japonaise ait produit des analyses dans ce cadre, quand elle cherchait à organiser l'histoire japonaise en termes de «stades d'évolution sociale » des sociétés passées, est certain. Mais il n'en pas certain que la prégnance de la vision marxiste de l'histoire ait été réellement déterminante : comme nous l'avons dit, l'anthropologie physique a été directement influencée par les modèles matérialistes de la biologie, dont elle fait partie, et notamment par le Darwinisme et par le Néo-Lamarckisme.

istant sur les mythes fondateurs de la dynastie imperiale, en surveillant de très près les mentions relatives à la Protohistoire dans les manuels d'histoire ${ }^{79}$, ou en restaurant, en 1967, la célébration de la date censée marquer la fondation mythique du Japon (Kigensetsu 紀元節, le 11 février), le Parti libéral-démocrate a développé après 1955 une politique qui fut perçue comme un retour vers une "histoire centrée sur l'empereur " (kōkoku shikan 皇国史観 $)^{80}$. Ceci joua un rôle certain dans l'escalade entre les « deux nationalismes », le populaire contre le monarchique, et explique en partie la vigueur déployée par les universitaires pour défendre le discours « autochtoniste ». Au travers de la critique de l'idéologie centrée sur l'empereur, les marxistes et les libéraux d'après la décolonisation transférèrent ainsi l'idée de continuité, de la lignée impériale (discours dominant avant 1945) vers le « peuple». Ils contribuèrent ainsi à l'élaboration d'une «histoire nationale» au sens strict du terme, c'est-à-dire une histoire ethnocentrée dont le seul héros est « le peuple».

Rappelons en outre que l'« autochtonisme » japonais n'était pas accepté qu'au Japon, mais fut également bien accueilli en Corée, où l'ouvrage d'Inoue susmentionné a d'ailleurs été traduit, et pas uniquement du fait du poids accordé à l'idée de l'homogénéité ethnique du "peuple coréen »: il constituait en effet une critique de l'argumentaire des «origines communes nippo-coréennes» utilisé durant la colonisation. On comprend certes les motivations d'une telle position dans la Corée postcoloniale. On peut se demander toutefois si la critique de la colonisation doit nécessairement passer par la construction d'un discours nationaliste chez les anciens colonisés.

Ces discours «autochtonistes » eurent une influence certaine sur l'opinion publique japonaise dans les décennies 1950-1970, c'est-à-dire sur la génération d'après la guerre et la colonisation, mais il ne faudrait pas pour autant surestimer le poids des scientifiques: de tels discours furent rendus possibles parce qu'ils exprimaient au niveau universitaire des idées déjà intériorisées par la société. 
Entre 1984 et 1990, l'anthropologie physique japonaise passa du modèle de la microévolution de Hasebe et Suzuki vers un nouveau paradigme. Hanihara, qui avait succédé à Suzuki à la tête de la section Anthropologie à l'Université de Tōkyō en 1972, soutint pour la première fois en 1984 son modèle dit de la «structure duale " $^{81}$. Il était aidé par une nouvelle génération de chercheurs, tel Koyama Shūzō 小山修三 (né en 1939) qui considérait, dans sa thèse de doctorat de 1976 puis dans un ouvrage de 1984, qu'il y avait eu une décroissance interne du volume de la population de l'archipel à la fin de la période Jōmon (c'est-à-dire avant le Yayoi ancien, donc sans relation avec des facteurs externes tels qu'une invasion ${ }^{82}$. Hanihara essuya rapidement de nombreuses critiques évoquant en particulier l'impossibilité technologique d'effectuer la traversée du continent vers l'archipel au $\mathrm{III}^{\mathrm{e}}$ siècle avant notre ère. Il s'appuya alors sur les recherches menées par Kanaseki et, à partir de simulations informatiques, put établir qu'environ un million de migrants et envahisseurs auraient pu arriver sur l'archipel durant la période Yayoi ${ }^{83}$. Son explication, sévèrement controversée dans un premier temps, fut finalement largement acceptée par les chercheurs au début de la décennie 1990. Hanihara pu alors compter sur des soutiens scientifiques importants: le généticien Omoto Keiichi 尾本惠市 (né en 1933), l'anatomiste Dodo Yukio 百々幸雄 (né en 1944), les chercheurs de l'International Research Center for Japanese Studies (Kokusai Nihon bunka kenkyū sentā 国際日本文化研究センター) de Kyōto, ainsi que de grands historiens ${ }^{84}$.

39 Le modèle de Hanihara fut le premier à considérer les variations géographiques à l'intérieur de l'archipel japonais en corrélation avec une réflexion sur l'ethnogenèse du peuple japonais. Il concluait que deux «races» s'étaient bien métissées durant la période Yayoi, mais que ce métissage n'était pas uniforme: l'Ouest du Japon renfermerait davantage de personnes correspondant au type morphologique de la « race Yayoi » (grands et dolichocéphales), tandis que le Nord-est du Japon contiendrait davantage de caractères de la "race Jōmon ", selon une pente progressive exprimant le « degré de métissage » entre les deux pools génétiques. Ce faisant, en totale opposition avec les discours de Suzuki et de Kanaseki qui rejetaient les Aïnous en dehors du corps national japonais, Hanihara fut amené à intégrer les populations d'okinawa et les Aïnous de Hokkaidō au sein des Japonais au sens biologique du mot, en expliquant qu'ils étaient les descendants des populations du Jōmon ${ }^{85}$.

Bien que ce modèle permît de sortir du "mythe du peuple homogène ", il montrait cependant la persistance d'analyses racialistes au Japon, y compris dans l'anthropologie et l'archéologie des années récentes. Cela ne l'empêcha pas d'avoir une influence certaine sur des anthropologues physiques non japonais: Christy Turner, de l'Arizona State University, dont le travail complète celui de Hanihara en divisant l'Asie en deux grands types raciaux nord et sud suivant la forme des dents ${ }^{86}$; Mark J. Hudson de l'Université de Nishi Kyūshū, qui comme Hanihara, rejette l'idée d'homogénéité ethnique et se concentre sur les processus, tout en continuant à penser « les Japonais » selon une approche biologique de la nation ${ }^{87}$.

Quelles sont les raisons de ce nouveau paradigme alors que l'obsession vis-à-vis de l'« ethnogenèse » des Japonais est, elle, condamnée à tourner en rond? Dans le renouvellement des années quatre-vingt-dix, il ne faut pas surestimer le poids du travail des généticiens. Ceux-ci évoluent de façon parfois contradictoire : Omoto rejette 
le concept de race et critique les travaux de Turner et de Hanihara à ce titre, au-delà de la terminologie employée par ces auteurs ${ }^{88}$. Hōrai Satoshi 宝来聡 (né en 1946), du Centre national de la recherche génétique, tente (comme Omoto) d'établir les écarts génétiques entre les populations (et non d'identifier des races) et explique notamment, avec une formule qui montre l'intérêt persistant pour le classement des populations : "notre histoire est gravée dans nos gènes ${ }^{89}$. Mais d'autres généticiens, tel Nei Masatoshi 根井正利 (né en 1931) de la Pennsylvania State University, analysent au même moment l'évolution des Japonais de manière endogène en invoquant un processus de microévolution depuis la préhistoire Jōmon ${ }^{90}$, ce qui fit douter Omoto du bien-fondé de sa critique envers Suzuki ${ }^{91}$. On le comprend: tout comme les anthropologues physiques, les généticiens peuvent ainsi construire et reconstruire les «races». Et si le travail mené par Omoto pour le ministère de l'Éducation en 1997-200092 prolonge sa recherche antérieure ${ }^{93}$, il ne semble apporter aucune conclusion à un débat qui relève plutôt de l'obsession identitaire moderne. Il faut plutôt évoquer, pour comprendre l'évolution des théories et le déclin des thèses de Suzuki, l'apparition dans les années quatre-vingt de problématiques insistant sur la "pluralité » qui ne sont sans doute pas sans rapport avec le retour de la mémoire de l'empire colonial japonais, avec la venue de nouveaux immigrés, et avec l'éclosion d'un débat sur les responsabilités japonaises. Dès lors, la position d'enfermement sur soi n'était plus tenable, et, peut-on penser, c'est l'éloge du métissage qui est revenu une nouvelle fois en avant. Cette situation n'est pas sans rappeler celle de la France des années 2000, où le débat sur la «République coloniale » est lié à celui sur la composition « ethnique » de la nation.

\section{Nation, obsession des " origines » et débats d'« ethnogenèse »}

Sciences sociales, discours universitaires et opinion publique (même si celle-ci suit un rythme différent) s'éloignent aujourd'hui au Japon de ces paradigmes ethnocentrés affirmant l'enracinement du " peuple » dans le « sol national ». Cependant, force est de constater que l'historiographie et l'archéologie coréennes ont connu de leur côté une réethnicisation de leur discours, évoquant aussi un "peuple-nation " coréen, ethniquement homogène depuis 4000 ans et qui n'aurait jamais connu de minorités en son sein. En Corée aussi, c'est bien l'obsession des " origines » ou de l'« ethnogenèse " qui motive les chercheurs, comme l'a montré le travail de Pai Hyung-Il ${ }^{94}$. En outre, si les historiens européens ont bien étudié le processus de formation des nations modernes à la suite des travaux d'Eric Hobsbawm au début des années quatre-vingt ${ }^{95}$, certains représentants au Conseil de l'Europe et archéologues de l'European Association of Archæologists ont commencé à s'interroger récemment sur une "identité celte » de l'Europe remontant au Néolithique, comme s'en est inquiété l'historien britannique Paul Graves-Brown ${ }^{96}$.

Dès lors, la rigueur impose de ne pas voir de la spécificité là où elle n'existe pas, de ne pas produire de toutes pièces de l'altérité, quand les phénomènes étudiés peuvent s'expliquer par de simples différences de degrés. Il s'agit surtout d'analyser des processus de reconstruction identitaire et les discours associés, au sein de pays qui furent autrefois des puissances coloniales à peu près en même temps et qui se sont ensuite tous reposé la question du peuplement et de la nation. Dépassant les 
oppositions binaires de naguère entre "avant-guerre » et "après-guerre ", ou entre «domination coloniale » et « libérations nationales »- deux paires de termes souvent confondues pour le cas du Japon -, il semble aujourd'hui nécessaire, du point de vue de l'historien, de reconsidérer les discours comme des produits de leur temps. Les discours politiques touchant aux sociétés ne peuvent être dissociés de leur contexte d'émission, contexte qui surdétermine leur contenu ainsi que les appropriations dont ils sont l'objet.

Si la colonisation est aujourd'hui critiquée pour avoir dévoré les identités, c'est parce que la décolonisation et la période postcoloniale ont vu éclore des revendications de défense de "l'identité nationale » chez les anciens colonisés. Le processus historique que fut la colonisation avait cependant aussi ouvert la porte à l'assimilation, construisant par là même des identités nouvelles (liées à la métropole coloniale ou bien en opposition à celle-ci) rarement nationales autrefois. L'émancipation nationale - qui ne peut pas, au Xx $x^{e}$ siècle, être dissociée de la création desdites nations - ne semble, par contre, pas capable d'avancer sans procéder par une nouvelle essentialisation de la notion de "peuple » ou sans définir ce qui est völkisch. Comme on l'a vu, ce processus n'est pas le seul fait des anciennes colonies: les anciennes métropoles ont connu dans un même temps un processus homologue de réethnicisation de leur identité nationale. On a évoqué le cas de l'Angleterre, mais au moment même où Suzuki s'exprimait devant la Société japonaise d'anthropologie pour le centenaire de celle-ci, l'historien Fernand Braudel (1902-1985) expliquait dans son ouvrage L'Identité de la France que les Français s'étaient racialement constitués au Néolithique et que «l'occupation romaine » ou les récentes vagues d'immigration, depuis la fin du XIXe siècle, n'avaient eu aucun impact ramenées à la lignée ininterrompue du sang français ${ }^{97}$.

Ainsi, les continuités et les ruptures entre l'époque de la colonisation et la période qui suivit ne sont pas ce qu'elles semblaient être, pour au moins deux raisons. Premièrement, il existe dans tous les cas de figure une corrélation étroite entre pratique scientifique et idéologie, qui fait que le discours savant n'est jamais libre ou neutre par rapport à son contexte ou à son époque ; deuxièmement, il en découle qu'un discours scientifique orthodoxe peut avoir un rôle critique, à une autre époque et dans un autre contexte: ce fut le cas de Kanaseki après la décolonisation. Les sciences exactes telle l'anthropologie physique, tout comme les sciences humaines, sont elles aussi un miroir de la société : les chercheurs et les modèles acquièrent une certaine popularité parce que la société tente de se réfléchir et de se reconstruire via ces modèles et discours. Ainsi en alla-t-il de Hasebe, Inoue ou Suzuki dans les décennies 1950-1970 quand le Japon « oubliait » l'empire colonial pour se reconstruire sur l'archipel. Ce phénomène est à l'origine des Nihonjin-ron, c'est-à-dire de l'ensemble hétéroclite de discours qui tentent tous de cerner une "spécificité " nationale japonaise ${ }^{98}$. Dès qu'ils traitent de la société, les savants suivent certaines problématiques parce qu'ils sont eux-mêmes membres de cette société, plutôt qu'ils ne l'influencent. Se met ainsi en place une interaction à deux sens entre les discours des scientifiques et la communauté nationale, interaction qui montre que les savants ne vivent vraiment pas dans des tours d'ivoire, mais bien au cœur de la société. Ils sont les artisans actifs de sa définition et de son autoreprésentation, et fournissent des modèles qui viennent confirmer des idées déjà admises. Dans ces débats sur l'« ethnogenèse », le problème ne concerne pas tant la méthode ou la conclusion que la question. 


\section{NOTES}

1. Oguma Eiji 小熊英二, Tan.itsu minzoku shinwa no kigen 単一民族神話の起源 (Aux Origines du mythe du peuple homogène), Tōkyō, Shin.yō-sha 新曜社, 1995 ; «Nihonjin » no kyōkai 〈日本人〉 の境界 (Les Frontières de la japonité), Tōkyō, Shin.yō-sha, 1998.

2. Simon Kaner, "Beyond Ethnicity and Emergence in Japanese Archaeology", in Donald Denoon (dir.), Multicultural Japan: Palaeolithic to Postmodern, Cambridge, Cambridge Univ. Press, 1996, pp. 46-59, ici p. 49. Dans le même ouvrage, voir également Clare Fawcett, "Archaeology and Japanese Identity", pp. 60-77.

3. Voir notamment : Stephen Jay Gould, La Mal-mesure de l'Homme - Nouvelle Édition (1996), Paris, Odile Jacob, 1997 ; Léon Poliakov, Le Mythe aryen (1971), Paris, Calmann Lévy, 1994.

4. Sur la genèse du concept de race au Japon, voir Yonaha Jun 与那覇潤, « Kindai Nihon ni okeru “jinshu” gainen no henyō» 近代日本における「人種」概念の変容 (Évolution du concept de 《race» dans le Japon moderne), Minzokugaku kenkyū 民族学研究 (The Japanese Journal of Ethnology), vol. 68, n 1, Tōkyō, Nihon minzoku gakkai, 2003, p. 85-97. Rappelons que le terme de « race » n'est plus admis depuis les conférences de l'UNESCO du début des années 1950 et est rejeté aujourd'hui par la majorité de la communauté scientifique, même si d'autres catégories tentent de s'y substituer.

5. La période Jōmon est la période de la Préhistoire qui suit le Paléolithique. La période Yayoi correspond à la première partie de la Protohistoire $\left(\mathrm{du} \mathrm{VI}^{\mathrm{e}}\right.$ siècle av. notre ère au milieu du III ${ }^{\mathrm{e}}$ siècle de notre ère), et est suivie par la période Kofun (III ${ }^{\mathrm{e}}-\mathrm{VII}{ }^{\mathrm{e}}$ siècles). Voir les travaux de Laurent Nespoulous, in Jean-Paul Demoule et Pierre François Souyri (dir.), Archéologie et patrimoine au Japon, Paris, Maison des Sciences de l'Homme, 2008.

6. Kiyono, archéologue et médecin, était professeur à l'université impériale de Kyōto au lendemain de la Première Guerre mondiale. Torii est le plus grand anthropologue japonais du premier quart du $x^{e}$ siècle. Voir Arnaud Nanta, «Kiyono Kenji : anthropologie physique et débats sur la "race japonaise" à l'époque de l'empire colonial (1920-1945) », in Carole ReynaudPaligot (dir.), Histoire comparée de la pensée raciale, Paris, Institut Historique Allemand de Paris, 2007, et également du même auteur, "Torii Ryūzō : discours et terrains d'un anthropologue et archéologue japonais du début du $\mathrm{xx}^{\mathrm{e}}$ siècle », Bulletins et Mémoires de la Société d'Anthropologie de Paris, 2010 (22), p. 24-37. Sur l'anthropologie et l'archéologie japonaises de cette époque, voir : Terada Kazuo 寺田和夫, Nihon no jinruigaku 日本の人類学 (L'Anthropologie japonaise), Tōkyō, Kadokawa shoten 角川書店 1981 ; Kudō Masaki, Kenkyūshi - Nihon jinshuron 研究史 - 日本人種論 (Histoire des débats sur la race au Japon), Tōkyō, Yoshikawa Kōbunkan 吉川弘文館, 1979; Tsunoda Bun.ei 角田文衞 (dir.), Kyōto kōkogakuha 京都考古学派 (L'École d'archéologie de Kyōto), Kyōto, Yūzankaku 雄山閣, éd. augm. 1997 ; Arnaud Nanta, Débats sur les origines du peuplement de l'archipel japonais dans l'anthropologie et l'archéologie (décennie 1870 - décennie 1990), Thèse de doctorat, Paris 7 - GHSS, 2004, 4 vol. ; Sakano Tōru 坂野徹, Teikoku Nihon to jinruigakusha 帝国日 本と人類学者 (L’Empire japonais et les anthropologues), Tōkyō, Keisō shobō 勁草書房, 2005 ; Nanta, «L'Altérité aïnoue dans le Japon moderne (années 1880-1900), Annales HSS, 2006-1, Paris, EHESS, p. 247-273. Voir aussi Shinohara Tōru 篠原徹 (dir.), Kindai Nihon no tashazō to jigazō 近代日 本の他者像と自画像 (Images de l'altérité et de l'identité dans le Japon moderne), Tōkyō, Kashiwa shobō 柏書房, 2001; Arnaud Nanta, «De l'Importance des savoirs coloniaux à l'ère des impérialismes ", Ebisu, n 37, Tōkyō, Maison franco-japonaise, 2007, p. 99-114. Sur le Japon après 1945, John W. Dower, Embracing Defeat : Japan in the Wake of World War II, New-York, W. W. Norton, 1999 ; Michael Lucken, Anne Bayard-Sakai et Emmanuel Lozerand (dir.), Le Japon après la guerre, Picquier, 2006. 
7. Une chaire d'anthropologie avait été établie en 1892 mais il n'existait jusque-là pas de section d'Anthropologie officielle dans l'université, cette chaire relevant de la faculté de lettres.

8. Voir Terada, op. cit. (1981) ; Sakano, op. cit. (2005) ; Arnaud Nanta, Thèse de doctorat, op. cit.

9. Nanta, « Débats autour des fouilles archéologiques à Ōsaka, 1917-1920 », Ebisu, Tōkyō, Maison franco-japonaise, $\mathrm{n}^{\circ}$ 32, 2004, p. 25-63.

10. Voir : Oguma, op. cit. (1995) ; Yonemoto Shōhei 米本昌平, Matsubara Yōko 松原洋子 et als, Yūseigaku to ningen shakai 優生学と人間社会 (Eugénisme et sociétés humaines), Kōdan-sha 講談 社, 2000 ; Sakano, op. cit. (2005).

11. Hasebe, «Akashi-shi fukin nishi-Yagi saishinsei zenki taiseki shutsudo jinrui yōkotsu (sekkōgata) no genshisei ni tsuite» 明石市附近西八木最新世前期堆積出土人類腰骨（石膏型）の原 始性に就いて ( Au sujet du caractère primitif du bassin humain (moule en plâtre) découvert dans la couche du Pléistocène ancien de Nishi-Yagi, à proximité de la ville d'Akashi »), Jinruigaku zasshi (Revue d'anthropologie), Tōkyō, Nihon jinrui gakkai (Société japonaise d'anthropologie), 1948, vol. 60-1, p. 32-37.

12. L'Homme de Java et l'Homme de Pékin étaient alors respectivement appelés Pithecanthropus et Sinanthropus.

13. Weidenreich avait fui l'Allemagne nazie et pris la suite de Davidson Black (1884-1934) à la direction des fouilles à Zhoukoudian. Il partit ensuite aux États-Unis.

14. Site d'Iwajuku 岩宿遺跡, dans le département de Gunma. Cette découverte fut rendue possible par une première exhumation sur ce lieu, en 1946, d'objets paléolithiques travaillés par l'homme. Un archéologue amateur, Aizawa Tadahiro 相沢忠洋 (1926-1989), les avait trouvés sous la couche de cendres volcaniques qui recouvre la région du Kantō (rōmu sōローム層), alors que les chercheurs estimaient, avant 1945, ne rien pouvoir trouver sous cette strate, dont l'ancienneté n'était d'ailleurs pas bien comprise. Aizawa contribua ainsi à l'une des découvertes les plus importantes pour l'archéologie de l'époque, avec celle du site, cette fois protohistorique, de Toro 登呂遺跡 en 1943. En 1949, le Paléolithique était appelé «période pré-décors cordés » (pure-jōmon jidai プレ繩文時代) ou «époque pré-céramique » (sen doki jidai 先土器時代), et non « kyū sekki jidai ». Si le nom n'était pas encore fixé, la période était en tout cas bien dissociée du Jômon.

15. Les historiens et archéologues français, tels Jean-Paul Demoule ou Jean Guilaine, utilisent le terme "autochtonisme» pour désigner les discours affirmant la continuité du peuplement (national), ainsi que des dynamiques avant tout endogènes pour expliquer les grandes évolutions et transformation des sociétés humaines au sein d'un territoire. Sur cet autochtonisme en archéologie au Japon, voir Laurent Nespoulous, Une Histoire de la protohistoire japonaise - De la Genèse de l'agriculture à la formation des sociétés archaïques complexes, Thèse de doctorat, Inalco, Paris, 2007, p. 117-138. Voir également Jean Guilaine, "Des mythes... modernes ", in Jean Guilaine, Caïn, Abel, Ötzi L’héritage néolithique, Gallimard, Paris, 2011, p. 233-254.

16. Oguma, op.cit. (1995). On peut considérer ce terme d'Oguma comme un équivalent à " autochtonisme ».

17. Sur les historiens et la notion de «peuple» : Oguma, «Minshu» to «Aikoku» <民主>と<愛 国> (« Démocratie » et « Patriotisme »), Tōkyō, Shin.yō-sha, 2002.

18. Mark Hudson, Ruins of Identity. Ethnogenesis in the Japanese Islands, Honolulu, University of Hawai Press, 1999, p. 51. Un phénomène semblable - avec ses particularités - a été souligné dès la fin de l'empire colonial britannique. Voir à ce sujet Grahame Clarke, “The Invasion Hypothesis in British Archaeology", Antiquity, vol. 40, nº 159, Londres, Antiquity Publications, pp. 172-189. Voir aussi la réponse de Charles Francis Christopher Hawkes, "British Prehistory: The Invasion Hypothesis", Antiquity, Londres, Antiquity Publications, vol. 40, n 160, 1966, pp. 297-299.

19. Oguma, op. cit. (2002). 
20. Hasebe, Nihon minzoku no seiritsu 日本民族の成立, publié dans une série réputée progressiste : Shin Nihon shi kōza 新日本史講座 (Nouvelle histoire du Japon), Tōkyō, Chūō kōron-sha, vol.1, 1949, $75 \mathrm{p}$.

21. Hasebe, Nihonjin no sosen 日本人の祖先, Tōkyō, Iwanami shoten, 1951. La recherche présupposait l'unité raciale des populations qu'elle étudiait comme une évidence. Le rejet de la minorité aïnoue à l'extérieur de ces schémas est en ce sens significatif.

22. Le mot fut repris en Corée (kr. : minjok 민족) dans le cadre de la résistance à la colonisation.

23. Voir ma thèse de doctorat, op. cit.

24. Sur le Néo-Lamarckisme, qui n'est pas une théorie mais un groupe hétérogène d'idées, voir Antonello La Vergata, « Néo-Lamarckisme », in Patrick Tort (dir.), Dictionnaire du Darwinisme et de l'Évolution, Paris, PUF, vol. 2, p. 3185-3202.

25. Hasebe, op. cit. (1949), p. 46-47.

26. Les écrits de Kiyono de 1926-1949, influents à l'époque, penchaient en faveur d'un métissage originel durant la Protohistoire qui aurait ensuite débouché sur une homogénéisation ethnique par croisements endogènes.

27. Voir : Ève Gran-Aymerich, "Archéologie et préhistoire : les effets d'une révolution ", in Éric Perrin-Samindayar (dir.), Rêver l'archéologie au XIXe siècle : de la science à l'imaginaire, Saint-Étienne, Presses de l'Université de Saint-Étienne, 2001, p. 17-46.

28. Hasebe, op. cit. (1949), p. 58.

29. Sur ces points, voir: Claude Blanckaert (dir.), Les Politiques de l'anthropologie. Discours et pratiques en France (1860-1940), Paris, L'Harmattan, 2001 ; Stephen J. Gould, op. cit. (1997).

30. Suzuki avait étudié avant-guerre l'évolution progressive de la forme des coquillages, dont il avait jugé qu'elle avait eu lieu en absence de mélange génétique. Hiraizumi est un site célèbre de la fin $d u \mathrm{XI}^{\mathrm{e}}$ et $\mathrm{du} \mathrm{XII}^{\mathrm{e}}$ siècle. Les seigneurs de la région s'étaient fait momifier, ce qui permettait une analyse des corps.

31. Les populations non-japonaises du Nord de l'archipel, appelées «Emishi » («les Barbares») durant l'Antiquité, n'étaient pas des «Aïnous» mais des populations non soumises au pouvoir central. Les Aïnous se constituèrent comme entité culturelle distincte vers le $\mathrm{xv}^{\mathrm{e}}$ siècle à partir de l'ensemble des populations du nord.

32. Suzuki, Hone 骨 (Ossements), 1965, Tōkyō, Gakusei-sha 学生社, réédition augmentée, 1996, p. 146.

33. Suzuki (dir.), Zōjōji Tokugawa shōgun bo to sono ihin - itai 増上寺徳川将軍墓とその遺品・遺体 (Les tombes des shōgun Tokugawa, leurs objets et leurs dépouilles), Tōkyō, Tōkyō daigaku shuppankai, 1967.

34. Cette théorie avait été introduite par le médecin Erwin von Baelz (1849-1913) en 1883-1885, dans la série d'articles:»Die körperlichen Eigenschaften der Japaner «, Mittheilungen der deutschen Gesellschaft für Natur- und Völkerkunde Ostasiens, vol. 28, Berlin, Deutsche Gesellschaft für Natur- und Völkerkunde Ostasiens, 1883, p. 330-359 ; vol. 32, 1885, p. 35-103.

35. Sur l'historiographie dualiste, voir Poliakov, op. cit. (1971); Michel Foucault, Il faut défendre la société, Paris, Seuil, 1997.

36. La nouvelle archéologie israélienne se constituait alors en "archéologie nationale ». Elle était, elle aussi, à la recherche des ancêtres des Israéliens et des sites de l'État antique d'Israël, dans un travail associant activité scientifique et philologie (à partir notamment de l'Ancien Testament).

37. On a su ensuite que ce squelette (Mikkabi-jin三ヶ日人) se rattachait au Jōmon.

38. Les trois squelettes des Hommes de Minatogawa (Minatogawa-jin 港川人) datés de 18000 ans $\mathrm{BP}$, ont été retrouvés à Okinawa, ce qui pose un problème quant à leur représentativité pour penser la Préhistoire de l'archipel japonais.

39. Ce modèle est aussi connu au Japon sous le nom ikō-setsu 移行説 (c'est-à-dire «passage progressif », du morphotype Jōmon à celui du Yayoi). 
40. Suzuki, "Changes in the Skull Features of the Japanese People from Ancient to Modern Times”, 1956, texte compilé dans Suzuki Hisashi kokkaku jinruigaku ronbunshū 鈴木尚骨骼人類学論 文集 (Textes choisis de Suzuki Hisashi en anthropologie du squelette), Tōkyō, Therapeia てらぺ いあ, 1992, p. 325-332.

41. Suzuki, «Koseibutsugaku - Jinruigaku » 古生物学 人類学, in Oka Hidemichi 丘英通 (dir.), Dāuin shinkaron hyakunen kinen ronshū, ダーウィン進化論百年記念論集 (Sélection d'articles pour la commémoration des cent ans de la théorie de l'Évolution de Darwin), Tōkyō, Éd. de la JSPS, 1960, p. 167-176. Oka Hidemichi est le fils du célèbre biologiste et social-darwiniste Oka Asajirō 丘 浅次郎 (1868-1944).

42. Suzuki, « Nihonjin no kigen»日本人の起源 (Les origines des Japonais), Iwanami kōza - Nihon rekishi 岩波口座 日本歴史, Tōkyō, Iwanami shoten, 1964, vol. 23, p.1-48. L'année suivante, Ienaga débutait une série de trois procès contre le ministère de l'Éducation. On sait que son action visait la présentation de la Seconde Guerre mondiale dans les manuels d'histoire. Mais il reprochait également au ministère de vouloir retirer la Préhistoire des manuels pour faire commencer l'histoire japonaise avec les premiers empereurs mythiques.

43. Journal of the Faculty of Science, Section V (Anthropology), mars 1969, vol. 3-4, Tōkyō, Tōkyō daigaku shuppan-kai, pp. 279-309 + 7 planches. Dans ce même numéro, l'anthropologue Watanabe Naotsune 渡辺直経, de la Société d'anthropologie de Tōkyō, présentait un article intitulé : "Chronological Background for Studies on Microevolution and Population History in Japon", venant renforcer le propos de Suzuki sur le plan de la culture matérielle. Ibid., pp. 267-277. La langue employée dans les publications constitue d'ailleurs une caractéristique remarquable des pratiques universitaires d'après 1945 : en effet, au cours des années cinquante les anthropologues physiques japonais passèrent rapidement de l'allemand, dominant avant la guerre, à l'angloaméricain. Ceci montre la place croissante des États-Unis, alors que le poids de l'influence allemande sur la médecine mondiale était écrasant avant 1945. Tous les grands médecins japonais - la discipline qui fournit les anthropologues physiques - allaient jusque-là étudier en Allemagne ; Ardath Burks: The Modernizers: Overseas Students, Foreign Employees, and Meiji Japan, Londres, Westview, 1985.

44. Yoshioka Ikuo 吉岡邰夫, Nihon jinshuron no makuake 日本人種論の幕開け (Le Début des débats d'ethnogenèse au Japon), Tōkyō, Kyōritsu shuppan 共立出版, 1987, p. 14.

45. Suzuki, conférence principale pour le centenaire de la Société japonaise d'anthropologie: «Nihon jūmin no keisei katei»日本住民の形成過程, résumé dans : Jinruigaku zasshi, vol. 93-1, Tōkyō, Nihon jinrui gakkai, janvier 1985, p. 269-270.

46. Cette idée avait été formulée par Weidenreich qui pensait que l'humanité dans son ensemble connaissait un tel processus. Weidenreich, "The Brachycephalization of Recent Mankind", Southwest Journal of Anthropology, vol. 1-1, Albuquerque, Univ. of New Mexico Press, 1945, pp. 1-54. 47. Ce programme était supervisé par le médecin Uchimura Yūshi 内村祐之 (1897-1980) de l'Université de Tōkyō, qui avait déjà travaillé avec la JSPS (Nihon gakujutsu shinkōkai 日本学術 振興会) en 1934-1935 lors d'un grand programme de recherche ethnologique et raciologique sur les Aïnous ; Shinohara, op. cit. (2001).

48. Suzuki \& Ebara Akiyoshi 江原昭善, «Sōseiji no seitai keisoku» 双生児の生体計測 (Anthropométrie des jumeaux), in Sōseiji no kenkyū 双生児の研究 (Études des jumeaux), Tōkyō, Éd. du JSPS, 3 vol., vol. 2, 1954, p. 50-77. Les premières études sur les jumeaux au Japon remontent à 1935-1943.

49. Suzuki utilisa aussi des données issues d'études similaires menées par Otmar von Verschuer (1896-1969) au milieu des années trente au Kaiser-Wilhelm-Institut für Anthropologie, menschliche Erblehre und Eugenik, à Berlin. Von Verschuer fut une figure centrale de l'anthropologie physique allemande de l'époque du nazisme.

50. Il réaffirma cependant, de façon quelque peu contradictoire, l'idée que l'anthropométrie pouvait déterminer la nature raciale d'un individu: selon lui, le modulus (le rapport entre 
hauteur, largeur et longueur du crâne divisé par trois) serait constant au sein d'une race, au-delà des variations de forme ou de taille du crâne. Car le modulus serait selon lui umweltstabil (fixe) tandis que l'indice céphalique et les caractères morphologiques du crâne seraient umweltlabil (variables). En 1954, Suzuki utilisait encore la terminologie allemande dans ses articles, ce qui montre le poids de la langue allemande au sein de la génération d'avant-guerre.

51. Suzuki, op. cit. (1964), p. 34.

52. Sur les institutions de recherche anthropologiques et archéologiques en Corée coloniale, voir Nanta, "Savoirs et colonies: l'archéologie et l'anthropologie japonaises en Corée », in JeanJacques Tschudin et Claude Hamon (dir.), La Société japonaise devant la montée du militarisme, Paris, Philippe Piquier, 2007, p. 21-31; Kishimoto Mio 岸本美緒 (dir.), «Teikoku » Nihon no gakuchi「帝 国」日本の学知 (Les Savoirs de « l'empire » du Japon), 8 vol. , vol. 3 : Tōyōgaku no jijo 東洋学の磁 場 (Le Champ de l'orientalisme), Tōkyō, Iwanami shoten, 2006.

53. Sur ce point, voir Terada, op. cit. (1981); Sakano, op. cit. (2005); Nanta, op. cit. 2004.

54. Il est à noter que l'archéologie coloniale organisée par les Japonais est au fondement de «l'archéologie nationale » coréenne d'après l'indépendance, archéologie qui insiste, elle aussi, sur l'unité ethnique des Coréens.

55. Le nom de Kanaseki n'apparaît d'ailleurs pas une seule fois dans la Revue d'anthropologie de 1945 à 1962.

56. Nihon kōkogaku kōza 日本考古学講座, publiés par l'éditeur Kawade Shobō, et dirigés par Fujita, Gotō Shuichi 後藤守一 (1889-1960) et par Uehara Senroku 上原專淥 (1899-1975).

57. Sur ce point, voir plus bas, en quatrième partie.

58. Suzuki, «Jōmon jidai jinkotsu » 繩文時代人骨, Nihon kōkogaku kōza, Tōkyō, Kawade shobō 河 出書房, 1956, 7 vol. , vol. 3, p. 353-375.

59. Kanaseki, «Jinshu no mondai»人種の問題, Nihon kōkogaku kōza, op. cit. (1956), vol.4, p. 238-252.

60. Congrès « Nihonjin no kigen »日本人の起源; Kanaseki, «Yayoi jidai no Nihonjin » 弥生時代 の日本人 (Les Japonais de la période Yayoi), Igakkai hōkoku 医学会報告 (Bulletin de la Société de médecine), 1959, compilé dans Kanaseki, Nihon minzoku no kigen 日本民族の起源 (Les origines du peuple japonais), Tōkyō, Hōsei daigaku shuppan 法政大学出版, 1976, p. 57-73.

61. Hanihara, Nihonjin no naritachi 日本人の成り立ち (La Formation des Japonais), Tōkyō, Jinbun shoin 人文書院, 1995, p. 164-165.

62. Hasebe, op. cit. ( 1949), p. 3 et p. 61-71.

63. Kanaseki, op. cit. (1976), p. 95 et p. 129-130.

64. On sut ensuite que Kō était un site paléolithique. André Leroi-Gouhran (dir.), Dictionnaire de la préhistoire, Paris, PUF, 1988, entrée « Kou ».

65. Nanta, « Débats autour des fouilles... », op. cit. (2004).

66. Wajima Seiichi 和島誠一 (dir.), Nihon kōkogaku kōza, Kawade shobō shinsha, 7 vol. , 1966.

67. Sur Imamura et Suzuki Makoto : Nanta, « Savoirs et colonies... », op. cit. (2007).

68. Nagai, « Nihonjin no sosen o saguru »日本人の祖先を探る (À la recherche des ancêtres des Japonais), in Kokubu Naoichi 国分直一 et Okamoto Tarō 岡本太郎 (dir.) Nihon bunka no rekishi 1 Daichi to jujutsu 日本文化の歴史 1 . 大地と呪術 (Histoire de la culture japonaise, vol. I : le sol et la magie), Tōkyō, Gakushū kenshū-sha 学習研修社, 1969, p. 239-248.

69. Naitō, «Seihoku kyūshū shutsudo no yayoi jidai jinkotsu» 西北九州出土の弥生時代人骨 (Les squelettes de la période Yayoi découverts au nord-ouest de Kyūshū), Tōkyō, Jinruigaku zasshi, vol. 79-3, Nihon jinrui gakkai, 1971, p. 236-248.

70. Hasebe décéda en 1969.

71. Le modèle de la microévolution fut par exemple exposé et soutenu en 1967 dans la revue Iden 遺层 (Hérédité), dont le directeur de publication était alors Oguma Mamoru 小熊捍 (1886-1971), premier président du Centre national de la recherche génétique (Kokuritsu idengaku kenkyūjo 国 立遺层学研究所), fondé en 1949. 
72. Le muséum (fondé en 1871) servit de vecteur à ce discours, par exemple avec l'exposition 《Nihon jinrui shi ten»日本人類史展 (Histoire de l'Homme au Japon), qui s'y tint du 20 octobre au 13 novembre 1973 avant de parcourir le reste du Japon et qui exposait le modèle de la microévolution des Japonais.

73. Par ex. : Ienaga Saburō, Nihon bunka shi 日本文化史 (Histoire de la culture japonaise), Tōkyō Iwanami shoten, 1959.

74. Maruyama a exposé l'idée autochtoniste dans ses séminaires à l'Université de Tōkyō, publiés sous le titre : Maruyama Masao kōgi roku 丸山眞男講義録, Tōkyō, Tōkyō daigaku shuppan-kai ; notamment les vol. 4 et 5, 1998-1999.

75. Dans son ouvrage Nihongo no kigen 日本語の起源 (Les origines de la langue japonaise) de 1957, Ōno discutait des « origines » de la langue japonaise en remontant jusqu'à une « langue Jōmon » pensée en association à une "race » autochtone. L'édition " révisée » de 1994 a vu disparaître tous les chapitres où Ōno discutait de la race.

76. Oguma, op. cit. (1995).

77. Inoue, Nihon no rekishi 日本の歴史, Tōkyō, Iwanami shoten, 1963-1966, 3 vol., vol. 1, 1963, p. 3-4. Sur Inoue, voir l'article de Tristan Brunet : http://cipango.revues.org/1081.

78. Andrew Barshay, The Social Sciences in Modern Japan -The Marxian and Modernist Traditions, Berkeley, Univ. of California Press, 2004.

79. Ce point, très peu connu dans les débats sur les manuels japonais car il est «purement national ", a eu autant d'importance que les questions relatives à l'histoire contemporaine et notamment à la responsabilité de guerre dans la première phase des procès sur les manuels.

80. Voir notamment le propos militant de l'archéologue Kondō Yoshirō 近藤義郎, dans : «Sengo Nihon kōkogaku no hansei to kadai » 戦後日本考古学の反省と課題 (Introspection et thèmes de recherche chez l'archéologie d'après la guerre), 1964, compilé dans Kondō Yoshirō, Nihon kōkogaku kenkyū josetsu 日本考古学研究序説 (Préface pour la recherche archéologique au Japon), Tōkyō, Iwanami shoten, 1985, p. 444-487. Notons que Ienaga et Inoue, dont il a déjà été question, réagirent de façon très critique à l'élaboration d'une date anniversaire de la fondation du pays.

81. Nijū kōzō moderu二重構造モデル ; Hanihara, Nihonjin no kigen 日本人の起源 (Les Origines des Japonais), Tōkyō, Asahi shuppan-sha, 1984. Le terme anglais Dual Structure Model ne fut employé qu'à partir de 1991.

82. Sa thèse de doctorat fut soutenue à l'Université de Californie (Berkeley). Cf. également Koyama, Jōmon jidai 縄文時代 (La période Jōmon), Tōkyō, Chūō kōron-sha 中央公論社, 1984.

83. Hanihara, "Estimation of the Number of Early Migrants to Japan: a Simulative Study", Jinruigaku zasshi, vol. 95, nº 3, Tōkyō, Nihon jinrui gakkai, 1987, pp. 391-403.

84. Hanihara, « Nihonjin no keisei » (La formation des Japonais), in Amino Yoshihiko 網野善彦 et Asao Naohiro 朝尾直弘 (dir.), Iwanami kōza - Nihon tsūshi 岩波講座 ·日本通史 (Cours Iwanami d'histoire du Japon), Tōkyō, Iwanami shoten, 25 vol. , 1995, vol. 1, p. 83-114.

85. Il avait développé cette idée dès 1971 à l'Université de Hokkaidō, lors d'un symposium sur le sujet: Hokkaidō daigaku tosho kankōkai 北海道大学図書刊行会, Ainu - sono kigen to bunka keisei アイヌーその起源と文化形成 (Aïnous: leur origine et la formation de leur culture), Sapporo, Hokkaidō daigaku tosho kankōkai, 1972.

86. Christy G. Turner, George R. Scott, The Anthropology of Modern Human Teeth: Dental Morphology and its Variation in Recent Human Populations, Cambridge, Cambridge Univ. Press, 1997.

87. Le travail de Hudson vise à mettre en lumière l'« ethnogenèse " (ethnogenesis) des Japonais c'est-à-dire la formation et le développement des "core biological and linguistic populations » au Japon entre 400 avant notre ère et 1200 ; Hudson, op. cit. (1999), p. 11. Il est malaisé de traduire la formulation «core population » utilisée par les anthropologues physiques anglo-saxons. Ce mot de «core» renvoie à l'idée de population «noyau », c'est-à-dire au "fondement » d'un groupe humain dont elles constitueraient la "base» fixe et solide malgré les variations de surface. 
Hudson a été critiqué par Kaner (1996, art. cit.), qui constitue, à notre connaissance, la seule critique existante de ces approches par un spécialiste anglo-saxon.

88. Omoto, "The Rise and Fall of the Biological Concept of Race", Japan Review, n ${ }^{\circ}$ 9, Kyōto, Kokusai Nihon bunka kenkyū sentā, 1997, pp. 65-73.

89. Hōrai, « Mitokondria DNA kara mita Nihonjin no naritachi »ミトコンドリアDNAから見た日 本人の成り立ち (La Formation des Japonais d'après l'ADN mitochondriaque), in Dodo Yukio (dir.), Mongoroido no chikyū モンゴロイドの地球 (La Terre et les races mongoloïdes), vol.3, Tōkyō, Tōkyō daigaku shuppan-kai, 1995, p. 211-232, ici p. 211.

90. Nei, "Genetic Polymorphism and the Origin and Evolution of Major Ethnic Groups", in Hanihara Kazurō et Sydney Brenner (dir.), The Origin and Past of Modern Humans as viewed from DNA, Singapore, World Scientific, 1995, pp.71-91. La position «autochtoniste» de Nei attire d'autant plus l'attention qu'il s'agit d'un généticien reconnu.

91. Omoto, «Bunshi jinruigaku kara mita Nihonjin no kigen» 分子人類学から見た日本人の起 源 (Les origines des Japonais d'après l'anthropologie moléculaire), in Sahara Makoto 佐原真 et al. (dir.), Kodaishi no ronten 古代史の論点 (Points de controverse sur l'histoire ancienne), Shōgakkan 小学館, 1999, p. 40-70, notamment p. 57-58.

92. Omoto (dir.), Nihonjin oyobi Nihon bunka ni kansuru gakusaiteki kenkyū 日本人および日本文化 に関する学際的研究 (Étude interdisciplinaire sur les origines des Japonais et de leur culture), vol. 1, Monbu kagaku-shō 文部科学省, Kyōto, International Research Center for Japanese Study, 2002.

93. Omoto (dir.), Interdisciplinary Perspectives on the Origins of the Japanese, Kyōto, International Research Center for Japanese Study, 1999.

94. Pai Hyung-Il, Constructing "Korean" Origins: a Critical Review of Archaeology, Historiography, and Racial Myth in Korean State-Formation Theories, Cambridge (Mass.), Harvard Univ. Asia Center, 2000.

95. Eric Hobsbawm et Terence Ranger (dir.), The Invention of Tradition, Cambridge, Londres, Cambridge Univ. Press, 1983.

96. Paul Graves-Brown (dir.), Cultural Identity and Archceology: the Construction of the European Communities, Londres, Routledge, 1996, notamment pp. 12-17.

97. Braudel, L’identité de la France, 1986, Paris, Flammarion, 2 vol. , 1990, ici vol. 1, p. 66-67. « Ainsi, il y a eu une Gaule avant la Gaule, entendez une soudure réelle entre ce qui précède la Gaule et la Gaule elle-même. J'aurais tendance à croire [...] aux 5 millions d'habitants de la population préhistorique, vers - 1800. Ce qui voudrait dire que, pour l'essentiel, les jeux biologiques sont déjà conclus à la fin du Néolithique, que les mélanges ethniques sont en place, et y demeureront. Les invasions qui suivront, et notamment celle des Celtes [...] se perdront peu à peu dans la masse des populations déjà installées, soumises, rejetées parfois hors de leurs terres, mais qui resurgiront, s'étaleront, prospéreront à nouveau. Le nombre conserve sans doute. N'en sera-t-il pas de même vis-à-vis des Romains? Et non moins face aux invasions barbares du $\mathrm{V}^{\mathrm{e}}$ siècle, ou aux immigrés trop nombreux qui inquiètent la France actuelle? Ce qui compte c'est la masse, la majorité de la France ».

98. En français, on parle parfois de «nippologies». Voir à ce sujet Jacqueline Pigeot, «Les Japonais peints par eux-mêmes », Le débat, nº 23, 1983, p. 19-33. 


\section{RÉSUMÉS}

Après 1945 se développent au Japon des discours identitaires soulignant la spécificité, l'homogénéité et la continuité raciale du peuple japonais depuis la Préhistoire, appuyés par les développements de l'anthropologie physique.

After WWII, speeches about identity placed emphasize on the specificity, the racial homogeneity and the continuity of the Japanese people since prehistoric times. They were supported by developments in physical anthropology.

\section{INDEX}

\section{Index géographique : Corée}

キーワード : Hasebe Kotondo 長谷部言人 (1882-1969), Suzuki Hisashi 鈴木尚 (1912-2004), Kanaseki Takeo 金関大夫 (1897-1983), shokumin 殖民, kokka shugi 国家主義, Kankoku 韓国, Shōwa jidai 昭和時代 (1945-1989), shizen jinrui gaku 自然人類学, jinruigaku 人類学, rekishi 歴 史

Thèmes : anthropologie physique, anthropologie, histoire

Keywords : Hasebe Kotondo (1882-1969), Suzuki Hisashi (1912-2004), Kanaseki Takeo

(1897-1983), Colonization, Nationalism, Korea, Shōwa (1945-1989), Biological Anthropology, Anthropology, History

Mots-clés : Hasebe Kotondo (1882-1969), Suzuki Hisashi (1912-2004), Kanaseki Takeo (1897-1983), colonisation, nationalisme

Index chronologique : Shōwa (1945-1989) 